\title{
Comparative Study on Effect of Moist Heat Therapy and Acupuncture as an Adjuvant to a Comprehensive Naturopathy Treatment in Management of Chronic Neck Pain- A Randomized Control Trial
}

\author{
Dr. Jyothy Elizabeth Pullan ${ }^{1}$,Dr. Sujatha K.J ${ }^{2}$, Dr. Prashanth Shetty ${ }^{3}$, \\ Dr.Geetha B Shetty ${ }^{4}$ \\ ${ }^{\text {I}}$ (Department Of Naturopathy, SDM College of Natruopathy and Yogic Sciences/ \\ Rajiv Gandhi University Of Health Sciences, India \\ ${ }^{2}$ (Department Of Naturopathy, SDM College of Natruopathy and Yogic Sciences/ \\ Rajiv Gandhi University Of Health Sciences, India) \\ ${ }^{3}$ (Department Of Naturopathy, SDM College of Natruopathy and Yogic Sciences/ \\ Rajiv Gandhi University of Health Sciences, India) \\ ${ }^{4}$ (Department Of Naturopathy, SDM College of Natruopathy and Yogic Sciences/ \\ Rajiv Gandhi University Of Health Sciences, India)
}

\begin{abstract}
:
Background:Chronic neck pain is a common musculoskeletal disorder. The use of Naturopathy, Moist heat and Acupuncture is common, it is essential to understand individual contributions of therapies when used as an adjuvant to Naturopathy in alleviating chronic neck pain and improving quality of life.

Materials and Methods: Sixty subjects were assigned to either group 1 (Moist heat with Naturopathy) or group 2 (Acupuncture with Naturopathy). Subjects received treatments for ten days. Assessments were made before (baseline) and after intervention. The assessment tools included were Visual Analogue Scale (VAS), neck disability index (NDI), State Trait Anxiety Inventory (STAI) and Short form-36 (SF-36)

Results:Results were compared within groups, 1 and 2, at baseline and post intervention. The overall comparison between the groups was done using Mann-Whitney U Test.Group 2 has shown significant difference in STAI $(2.10 \pm 0.56)$ when compared to group $1(1.83 \pm 0.43)$ and group 1 has shown significant difference in emotional problems $(100.00 \pm 36.18)$ when compared to group $2(100.00 \pm 19.56)$.

Interpretation and conclusion: The study suggests that moist heat and acupuncture along with naturopathy intervention may be considered effective treatments for chronic neck pain.
\end{abstract}

Keywords:Acupuncture, Chronic neck pain, Moist heat therapy,Naturopathy, State and Trait Anxiety Inventory

\section{Introduction}

Neck pain is one of the most common and painful musculoskeletal condition where the underlying cause of disease or abnormal anatomical structure are unidentified, hence, classified as 'non-specific'. Various causes for neck pain have been described and include osteoarthritis, discogenic disorders, trauma, tumors, infection, myofascial pain syndrome, torticollis and whiplash. Neck pain is defined as pain arising in a region bounded superiorly by the superior nuchal line, laterally by the lateral margins of the neck and inferiorly by the imaginary transverse line through the T1 spinus process. Pain is categorized by its duration, as acute when lasting up to 6 weeks, sub-acute when lasting from 6 weeks to 3 months and chronic when lasting for more than 3 months. It is estimated that $22 \%$ to $70 \%$ of the population are likely to have neck pain during their lifetime. ${ }^{[1]}$ The incidence and Prevalence of pain increases with age and is most common in women around the fifth decade of life. ${ }^{[2]}$ In modern social life, stress factors contribute to neck pain. ${ }^{[3]}$ Chronic pains have a negative impact on the quality of life and to high levels of anxiety, depression, and occupational dysfunction. ${ }^{[4]}$

Complementary and alternative medicine (CAM) includes a collection of therapies, practices that are not considered part of conventional medical practice and is becoming widespread and commonly used to treat musculoskeletal disorders, including back and neck pain, joint pains like arthritis. ${ }^{[5,6]}$ Naturopathy, one among complementary therapy deals with many back and neck pain patients as a first line of treatment. ${ }^{[7]}$ Naturopathy is a system of man building in harmony with constructive principles of nature on physical, mental, moral and spiritual planes of living and consists of treatment modalities like diet therapy, fasting therapy, mud therapy, hydrotherapy, massage therapy, acupressure, acupuncture, chromo therapy, and magnet therapy ${ }^{[8]}$

Moist heat can be from a moist heating pad, damp towel heated in a microwave oven, a hot shower or a hot bath. Physical therapists wrap moist hot packs in several layers of towels and apply them directly on the area at 75- 
$80^{\circ} \mathrm{C}$ for $20-30$ minutes that needs treatment. ${ }^{[9]}$ Acupuncture is an ancient Chinese medical technique with a history of over 2,000 years. The term "acupuncture" is derived from the Latin word acus, meaning a sharp point, and puncture, meaning to pierce. It can be defined as a technique of inserting and manipulating fine filiform needle into specific points on the body and to relieve pain for various therapeutic purposes. ${ }^{[10]}$

\subsection{Subjects:}

\section{Methodology}

Seventy one subjects with ages ranging between 19-60 years participated in the study. They were screened through a routine medical checkup and those satisfying diagnostic criteria for chronic neck pain were recruited.

\subsubsection{Description Of Subjects Including The Selection Of Sample From The Population:}

Study population was selected from Inpatient facility of Sri Dharmasthala Manjunatheshwara Yoga and Nature Cure Hospital, Shanthivana, Dharmasthala. Out of seventy four subjects, sixty were recruited for the study based on inclusion and exclusion criteria.

\subsubsection{Ethical Considerations:}

Subjects who fulfilled the inclusion criteria were informed regarding the study and intervention to be used. They were given the opportunity to ask any question and if they agreed to participate in the study they were asked to sign the informed consent form. All expressed their willingness to participate in the study by giving signed informed consent. Approval was obtained from Institutional Ethical Committee.

\subsubsection{Inclusion \& Exclusion Criteria:}

\subsubsection{Inclusion Criteria}

- Age group 19 to 60 years

- Both the genders

- Chronic neck pain

- Willingness to participate in trial by signing an Informed consent form.

\subsubsection{Exclusion Criteria}

-Presence of significant pathology, such as bone fracture, nerve damage or severe psychiatric condition, including clinical depression as determined by a physician.

- Back pain of other origin with systemic disease and neurological disorders.

- Direct impact trauma

- History of inflammatory arthritis of large joints

- Pregnancy

- Exposure to naturopathy, physiotherapy or acupuncture in the 6 months preceding entry.

- Obesity associated with back pain will be excluded.

\subsection{Design:}

A Prospective Randomized Controlled Trial, Randomization using manual method. There were equal numbers of subjects (30 each) in Group 1 (Moist heat with Naturopathy) and Group 2 (Acupuncture with Naturopathy). They were assessed at the baseline and after 10 days. ${ }^{[1]]}$

\subsection{Assessments}

\subsubsection{Primary outcome variables}

\subsubsection{Pain Analogue Scale:}

The visual analogue scale (VAS) provides a continuous scale for subjective magnitude estimation and consists of a straight line, the limits of which carry a verbal description of each extreme of the symptom to be evaluated.$^{[12]}$

\subsubsection{The Neck Disability Index}

The Neck Disability Index (NDI) is designed to measure neck-specific disability. The questionnaire has 10 items concerning pain and activities of daily living including personal care, lifting, reading, headaches, concentration, work status, driving, sleeping and recreation. ${ }^{[13]}$

\subsubsection{Secondary Outcome Variables:}

2.3.2.1 State Trait Anxiety Inventory (STAI):

The STAI is a validated 20 item self-report assessment device which includes separate measures of state and trait anxiety . ${ }^{[14]}$ 


\subsubsection{Short Form 36 (Sf 36).}

The SF-36 is a multi-purpose, short-form health survey with only 36 questions. It yields an 8-scale profile of functional health and well-being scores as well as psychometrically-based physical and mental health summary measures and a preference-based health utility index. ${ }^{[15]}$

\subsection{Intervention :}

The participants selected for the study were randomly assigned in to Group 1 and Group 2.

\subsubsection{Group 1:}

Moist heat application is commonly used treatment for chronic neck pain. Local application of heat or cold is indicated for thermal physiologic effects. The main physiologic effect is on superficial circulation because of the response of the temperature receptors in the skin and the sympathetic nervous system. According to the patient's sensitivity and symptoms heat and cold will be used.

\subsubsection{Group 2:}

Acupuncture : SI-1,3,6,14,15,GB-20,21,SJ-15,UB-10. ${ }^{[16]}$ The acupuncture points from the different meridians used along with $\mathrm{Ah}$ - Shi points for treating chronic neck pain. Selected naturopathic treatments specially designed for chronic neck pain are given to both the test groups.

Table 1.Naturopathy intervention protocol for 10 days.

\begin{tabular}{|c|c|c|}
\hline DAY & MORNING Rx & EVENING Rx \\
\hline 1 & Enema, Steam bath & Neutral immersion bath \\
\hline 2 & Enema, Full body + IR to neck & Alternate hip bath \\
\hline 3 & Enema, Sauna bath & Neutral hip bath \\
\hline 4 & Neutral Under Water Massage & Neutral half bath with salt \\
\hline 5 & Reclining steam bath & Revulsive compress to neck \\
\hline 6 & Neutral Douche To Back And Legs & Neutral spinal spray \\
\hline 7 & Steam Bath & Kidney pack \\
\hline 8 & Partial Massage To neck And arms+ IR & Neutral hip bath \\
\hline 9 & Salt glow oil massage & Revulsive compress to neck \\
\hline 10 & Neutral Immersion Bath & \\
\hline
\end{tabular}

Table 2. Diet protocol for 10 days

\begin{tabular}{|c|c|c|c|c|c|c|}
\hline DAY & 7:30 AM & 9 AM & $11 \mathrm{AM}$ & 2 PM & 4 PM & 6:30 PM \\
\hline 1 & $\begin{array}{l}\text { Lemon Honey } \\
\text { Juice }\end{array}$ & Ragi Ganji & $\begin{array}{c}\text { Boiled Diet, } \\
\text { Papaya, Buttermilk }\end{array}$ & $\begin{array}{l}\text { Carrot } \\
\text { Juice }\end{array}$ & $\begin{array}{l}\text { Cucumber, } \\
\text { Sprouts }\end{array}$ & $\begin{array}{l}\text { Boiled Diet, } \\
\text { Apple, Soup }\end{array}$ \\
\hline 2 & $\begin{array}{l}\text { Lemon Honey } \\
\text { Juice }\end{array}$ & Ragi Ganji & $\begin{array}{c}\text { Boiled Diet, } \\
\text { Papaya, Buttermilk }\end{array}$ & $\begin{array}{l}\text { Carrot } \\
\text { Juice }\end{array}$ & $\begin{array}{l}\text { Cucumber, } \\
\text { Sprouts }\end{array}$ & $\begin{array}{l}\text { Boiled Diet, } \\
\text { Apple, Soup }\end{array}$ \\
\hline 3 & $\begin{array}{l}\text { Lemon Honey } \\
\text { Juice }\end{array}$ & Ragi Ganji & $\begin{array}{c}\text { Raw Diet, Papaya, } \\
\text { Buttermilk }\end{array}$ & $\begin{array}{l}\text { Carrot } \\
\text { Juice }\end{array}$ & $\begin{array}{l}\text { Cucumber, } \\
\text { Sprouts }\end{array}$ & $\begin{array}{l}\text { Raw Diet, Apple, } \\
\text { Soup }\end{array}$ \\
\hline 4 & $\begin{array}{c}\text { Lemon Honey } \\
\text { Juice }\end{array}$ & Ragi Ganji & $\begin{array}{c}\text { Raw Diet, Papaya, } \\
\text { Buttermilk }\end{array}$ & $\begin{array}{l}\text { Carrot } \\
\text { Juice }\end{array}$ & $\begin{array}{l}\text { Cucumber, } \\
\text { Sprouts }\end{array}$ & $\begin{array}{l}\text { Raw Diet, Apple, } \\
\text { Soup }\end{array}$ \\
\hline 5 & $\begin{array}{l}\text { Lemon Honey } \\
\text { Juice }\end{array}$ & Ragi Ganji & Papaya, Buttermilk & $\begin{array}{l}\text { Carrot } \\
\text { Juice }\end{array}$ & $\begin{array}{l}\text { Cucumber, } \\
\text { Sprouts }\end{array}$ & Apple, Soup \\
\hline 6 & $\begin{array}{l}\text { Lemon Honey } \\
\text { Juice }\end{array}$ & Ragi Ganji & Papaya, Buttermilk & $\begin{array}{l}\text { Carrot } \\
\text { Juice }\end{array}$ & $\begin{array}{l}\text { Cucumber, } \\
\text { Sprouts }\end{array}$ & Apple, Soup \\
\hline 7 & $\begin{array}{l}\text { Lemon Honey } \\
\text { Juice }\end{array}$ & Ragi Ganji & $\begin{array}{c}\text { Raw Diet, Papaya, } \\
\text { Buttermilk }\end{array}$ & $\begin{array}{l}\text { Carrot } \\
\text { Juice }\end{array}$ & $\begin{array}{l}\text { Cucumber, } \\
\text { Sprouts }\end{array}$ & $\begin{array}{c}\text { Raw Diet, Apple, } \\
\text { Soup }\end{array}$ \\
\hline 8 & $\begin{array}{l}\text { Lemon Honey } \\
\text { Juice }\end{array}$ & Ragi Ganji & $\begin{array}{c}\text { Raw Diet, Papaya, } \\
\text { Buttermilk }\end{array}$ & $\begin{array}{l}\text { Carrot } \\
\text { Juice }\end{array}$ & $\begin{array}{l}\text { Cucumber, } \\
\text { Sprouts }\end{array}$ & $\begin{array}{l}\text { Raw Diet, Apple, } \\
\text { Soup }\end{array}$ \\
\hline 9 & $\begin{array}{l}\text { Lemon Honey } \\
\text { Juice }\end{array}$ & Ragi Ganji & $\begin{array}{c}\text { Boiled Diet, } \\
\text { Papaya, Buttermilk }\end{array}$ & $\begin{array}{l}\text { Carrot } \\
\text { Juice }\end{array}$ & $\begin{array}{l}\text { Cucumber, } \\
\text { Sprouts }\end{array}$ & $\begin{array}{l}\text { Boiled Diet, } \\
\text { Apple, Soup }\end{array}$ \\
\hline 10 & $\begin{array}{l}\text { Lemon Honey } \\
\text { Juice }\end{array}$ & Ragi Ganji & $\begin{array}{c}\text { Boiled Diet, } \\
\text { Papaya, Buttermilk }\end{array}$ & $\begin{array}{l}\text { Carrot } \\
\text { Juice }\end{array}$ & $\begin{array}{l}\text { Cucumber, } \\
\text { Sprouts }\end{array}$ & $\begin{array}{l}\text { Boiled Diet, } \\
\text { Apple, Soup }\end{array}$ \\
\hline
\end{tabular}

\section{Common Yoga Schedule For 10 Days}

\section{Loosening Exercises}

- Head \& Neck movements, Shoulder Rotation, Elbows Flexion \& extension

- Wrist up \& down, Rotation Movements, Finger clenching

- Spinal Twist, Hip up \& down, lateral bending, rotational movements

- Leg forward swing, sideward swing, Knees flexion \& extension

- Ankle up \& down, rotation, Toes clenching

\section{Breathing Exercises}

- Hands in and out breathing exercise, Hands stretch breathing exercise 
- Ankle stretch breathing exercise, Tiger breathing exercise

\section{Standing Series}

- Tadasana, Katichakrasana, Ardhachakrasana

\section{Supine Series}

- Folded legs Lumbar stretch

- Crossed leg lumbar stretch,

- Pawanamuktasana,

- Sethubandhasana With Breathing

5 Sitting series

- Vakrasana, Vajrasana, Ushtrasana

6 Prone series

- Bhujangasana, Makarasana, Dhanurasana

\section{Pranayama}

- Nadishodhana pranayama

- Bhramari Pranayama

\section{Relaxation technique}

- DRT (Deep relaxation technique)

\subsection{Data Extraction And Analysis}

\subsubsection{Data Extraction}

The data was collected using three primary outcomes variables and two secondary outcome variables. The assessments were collected on the first day (baseline data) and the end of 10 days (post data). The data was organized in Microsoft Excel Sheets (version 2010).

\subsubsection{Data Analysis}

Data were analyzed using IBM SPSS 21.0. The data was checked for normality and Mann -Whitney U test was employed to compare means between the two groups. For all the analysis, we present $95 \%$ confidence intervals and considered $\mathrm{p}<0.05$ as significant.

\section{Results}

The present study was conducted to compare and evaluate if moist heat and acupuncture along with naturopathy treatments had any influence on severity of pain, disability index, state (at the moment) anxiety and Quality of Life in patients with chronic neck pain for short term duration. Results were compared within two groups, group 1 (Moist heat with Naturopathy) and group 2 (Acupuncture with Naturopathy), wherein data was extracted at both baseline and post intervention. The overall comparison between the groups was done by using Mann-Whitney U Test which showed significant difference in STAI and emotional problem, a component of SF-36. Group 1 has shown significant difference in STAI $(1.83 \pm 0.43)$ when compared to group $2(2.10 \pm 0.56)$ and group 1 has shown significant difference in emotional problems $(100.00 \pm 36.18)$ when compared to group $2(100.00 \pm 19.56)$.

Fig. post intervention analysis

\begin{tabular}{|l|l|l|l|l|}
\hline $\begin{array}{l}\text { Variable post } \\
\text { intervention }\end{array}$ & $\begin{array}{l}\text { Group 1 } \\
\text { Median(SD) }\end{array}$ & $\begin{array}{l}\text { Group 2 } \\
\text { Median (SD) }\end{array}$ & $\begin{array}{l}\text { Mann Whitney u } \\
\text { test }\end{array}$ & P value \\
\hline VAS & $6.00(2.06)$ & $1.54(1.55)$ & 549.00 & 0.13 \\
\hline STAI & $1.83(0.43)$ & $2.10(0.56)$ & 298.50 & $0.02^{*}$ \\
\hline NDI & $15.75(18.71)$ & $14.75(10.14)$ & 521.50 & 0.29 \\
\hline PF & $70.00(36.18)$ & $75.00(11.54)$ & 380.50 & 0.30 \\
\hline PH & $65.00(33.22)$ & $75.00(29.71)$ & 378.00 & 0.28 \\
\hline EP & $100.00(36.18)$ & $100.00(19.56)$ & 319.50 & $0.01^{*}$ \\
\hline EF & $75.00(14.53)$ & $47.50(11.01)$ & 444.00 & 0.93 \\
\hline EW & $60.00(73.07)$ & $56.00(0.95)$ & 551.50 & 0.13 \\
\hline SW & $62.50(457.45)$ & $62.50(13.70)$ & 272.50 & 0.73 \\
\hline Pain & $55.00(0.08)$ & $55.00(16.37)$ & 377.50 & 0.28 \\
\hline GH & $60.00(0.75)$ & $65.00(12.98)$ & 422.50 & 0.86 \\
\hline
\end{tabular}


Fig. 7 Changes in post intergroup intervention in VAS, STAI, NDI

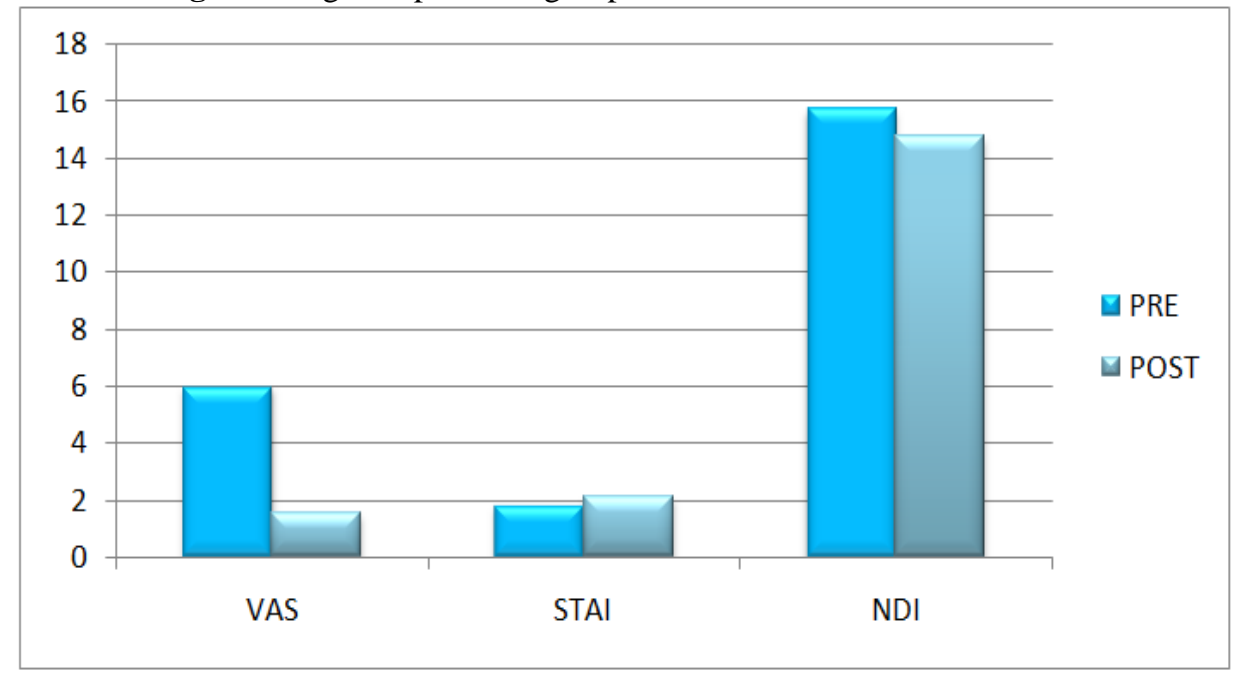

Fig.8 Changes in post intergroup intervention in SF-36

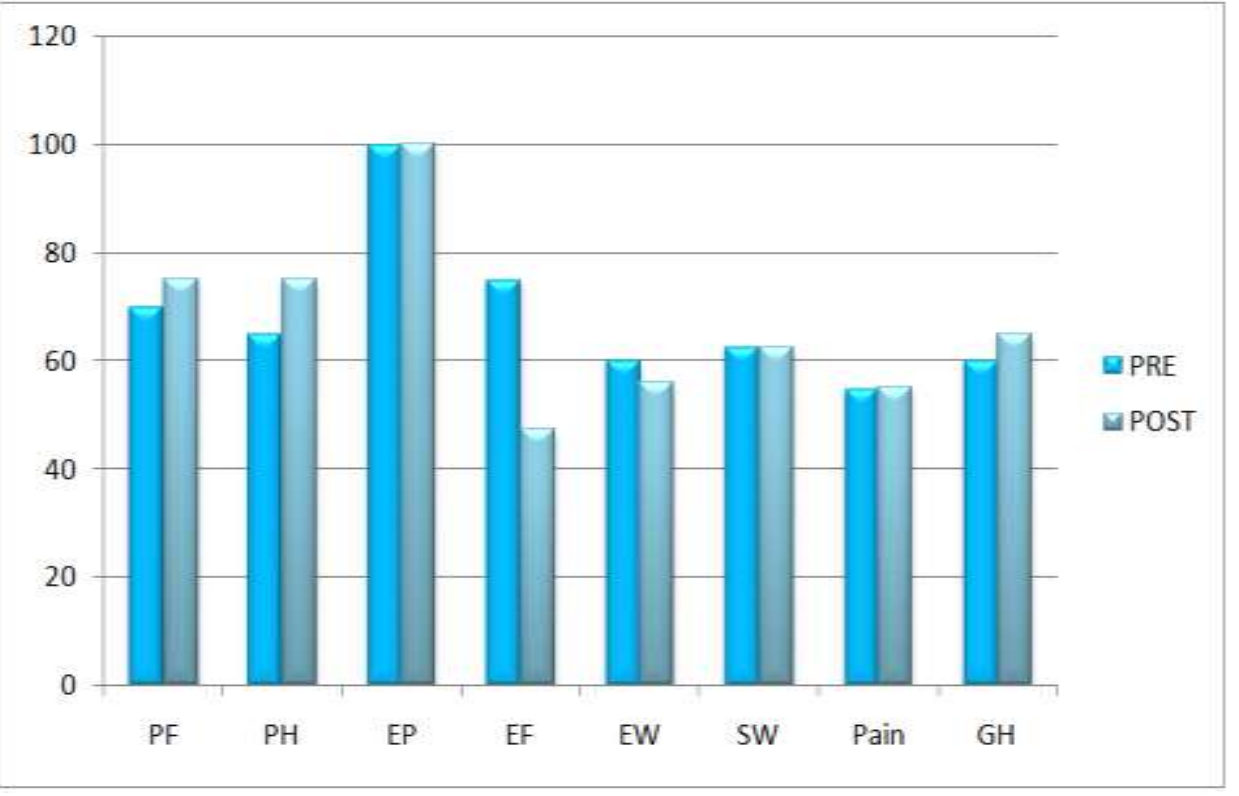

\section{Discussion}

The main aim of moist heat and acupuncture is in general to reduce pain intensity and severity of disability, improve the quality of life and health status in patient with chronic neck pain. We investigated the use of moist heat and acupuncture as an adjuvant to comprehensive naturopathy treatment before and after in patients with Chronic neck pain (CNP). We used self-reported Visual analogue scale, NDI (neck disability index), which has been used to assess neck disability), STAI (state and trait anxiety) and SF-36 (to measure health related quality of life). These methods have been reported to be most satisfactory for assessing the above same. In our present study, we found that both group 1 (Moist heat with Naturopathy) and group 2 (Acupuncture with Naturopathy) showed a difference with respect to pain severity, disability index, This study shows evidence that moist heat therapy or acupuncture when added to other conventional therapies, relieves pain and improves function better than the conventional therapies alone.

In this study of comparison between moist heat and acupuncture intervention, the data was statistically analyzed for different groups which showed significant results in state trait anxiety inventory. Moist heat group has shown significant results in reducing STAI $(1.83 \pm 0.43)$ when compared to acupuncture group $(2.10 \pm 0.56)$ and acupuncture group has shown significant results in emotional problems $(100.00 \pm 36.18)$ when compared to moist heat group $(100.00 \pm 19.56)$. The underlying mechanism for the reported benefits of moist heat may be due to the release of beta-endorphin $(\beta E)$ into the blood stream. In general, modalities of moist heat therapy might influence endorphin levels in the serum or in the cerebrospinal fluid; this is usually manifested by elevation with potential mitigation of pain. However, a causal relationship between the elevation of blood,

DOI: 10.9790/0853-150905139144 www.iosrjournals.org 143 |Page


cerebrospinal fluid or brain $\beta E$ levels and the onset of the analgesic action cannot be demonstrated with certainty. ${ }^{[17]}$ The insertion of needles into acupuncture points (special sites with denser innervation, more tightly packed connective tissue, and a richer content of Transient receptor potential vallinoid type-1(TRPV1) receptors) triggers mechanical stimuli that are transduced as neural signals along the large myelinated $A \beta$ - and A $\delta$-fibers. These signals ascend the dorsolateral tracts of the spinal cord and activate the supraspinal and higher centers involved in pain processing and from here, a few things happen, either in isolation or concurrently: modulation of the noradrenaline and 5 hydroxy tryptamine $(5-\mathrm{HT})$ signaling system, the production of endogenous neuropeptides acting upon the $\mu$-opioid and N/OPQ receptors, and the production of somatostatin and other related neurotrophins that together enhance the descending inhibition of nociception on the spinal afferents.

At the same time, inflammatory mediators produced by local micro trauma at the site of needle insertion will stimulate the unmyelinated C-fibers, which ascend the anterolateral columns of the spinal cord and activate the Diffuse noxious inhibitory control (DNIC), which both augments the general descending inhibitory control of nociception, and also perturbs the anti-correlated networks in the brain anchored on the insula to modulate the higher processing of pain. Last but not least, with repeated acupuncture treatments, neural plasticity develops in the spinal dorsal horn via the interplay of the( Long term potentiation) LTP/ (Long term depression) LTD of C-fiber potentials, alleviating nociceptive signals from the target site of treatment on a longterm basis. ${ }^{[18]}$

The study was able to prove the hypothesis that use of moist heat or acupuncture for a short term duration of 10 days as an adjuvant to naturopathy modality is effective in the treatment of CNP.

\section{Conclusion}

Both moist heat group and acupuncture showed improvement in VAS, NDI, STAI and SF-36, while acupuncture group showed better improvement in emotional problems within the group which suggests that moist heat and acupuncture along with naturopathy intervention can be considered as effective treatments in patients with chronic neck pain. The study is reported no adverse effects and is safe and effective though the subjects were small.

\section{References}

[1]. Petri Salo, Assessing physical capacity, disability and health related quality of life in neck pain. Studies in sports, physical education and health. (University of Jyvaskyla 2010).

[2]. Nikolai Bogduk, The anatomy and pathophysiology of neck pain, Physical medicine and rehabilitation clinics of North America, 14. 2003, 455-472.

[3]. Jiang-Ti Kong, Rosa N. Schnyer, Kevin A. Johnson, Sean Markey, Understanding central mechanism of analgesia using dynamic quantitative sensory testing: A review, Evidence based complementary and alternative medicine, 2013.

[4]. Inge E.Lam, Madeleon L.Peters, Johan W.S.Vlaeyan, Maarten V.Kleef, Jacob Patijn, Quality of life in chronic neck pain is more associated with beliefs about pain, than with pain intensity, European Journal of Pain, 9. 2005, 15-24.

[5]. Palmer KT, Walsh K, Bendall H, Cooper C, Coggon D. Back pain in Britain: comparison of two prevalence surveys at an interval of 10 years, British Medical Journal, 320. 2000, 1577-8.

[6]. Kessler RC, Davis RB, Foster DF, Van Rompay MI, Walters EE, Wilkey SA, Kaptchuk TJ, Eisenberg DM. Long-term trends in the use of complementary and alternative medical therapies in the United States, Annual Internal Medicine, 135(4), 2001. 262 - 68.

[7]. Boon HS, Cherkin DC, Erro J, Sherman KJ, Milliman B, et al, Practice patterns of naturopathic physicians: results from a random survey of licensed practitioners in two US States, BMC Complementary and Alternate Medicine, 4: 14.

[8]. National Center for Complementary and Alternative Medicine, Health Information http://nccam.nih.gov/health/whatis cam/. 52

[9]. Dr. R.N. Goel, Physiotherapy. (Vol -14th edition 2007, ISBN-81-901372-0-4, Shubham publications)

[10]. Ji-Sheng Han M.D, Acupuncture, In : T.R. Deer et al. Comprehensive Treatment of Chronic Pain by Medical, Interventional, and Integrative Approaches, American Academy of Pain Medicine, 2013, 867-880.

[11]. Petrofsky JS, Laymon M, Heat transfer to deep tissue: the effect of body fat and heating modality, Journal of Medical Engineering and Technology, 33(5), 2009.337-48

[12]. Cline (M.E), Standardization of visual analogue scale, Nursing Resustitation, 41.1992, 378.

[13]. Price DD, McGrath PA, Rafii A, Buckingham B, The validation of visual analogue scales as ratio scale measures for chronic and experimental pain, Pain , 17.1983,45-56.

[14]. Spielberger CD, Gorusch RL, Lushene RE, Manual for the State-Trait Anxiety Inventory. Palo Alto (CA): Consulting Psychologists Press; 1970 .The reliability of a linear analogue for evaluating pain, Anaesthesia, 21.1970, 701-711.

[15]. John E. Ware, Jr., Ph.D. SF-36 Health Survey Update. Available from: http://www.sf-36.org/tools/SF36.shtml

[16]. Whitfiled Reaves, Neck and shoulder pain: the levator scapuli muscle, Journal of Chinese Medicine, $2010 ; 94$.

[17]. Tamas B, Gyorgy N, Istvan B, Ildiko T, Eva K, Pal, The effect of physical therapy on beta- endorphin levels, European Journal of Applied Physiology, 100.2007,371 - 382.

[18]. Lawrence Leung, Neurophysiological Basis of Acupuncture-induced Analgesia - An Updated Review, Journal of Acupuncture Meridian Studies, 5. 2012, 261 - 270. 